\title{
Moringa oleifera: A Review Article on Nutritional Properties and its Prospect in the Context of Nepal
}

\author{
Kantilata Thapa*, Mousami Poudel and Prabin Adhikari \\ Agriculture and Forestry University, Rampur Chitwan, Nepal \\ *Corresponding Author: Kantilata Thapa, Agriculture and Forestry University, Rampur Chitwan, Nepal.
}

Received: September 16, 2019; Published: October 17, 2019

DOI: 10.31080/ASAG.2019.03.0683

\begin{abstract}
Moringa oleifera (M. oleifera) which is commonly known as Drumstick tree or Horse radish tree, is an angiospermic plant which belongs to family Moringaceae. This plant typically belongs to sub-himalayan Northen India, Pakistan, Bangladesh and Afghanistan. The Tropical and sub-tropical area of the world is suitable for the growth of this plant. The Terai, Siwalik, and Middle Mountain regions are the best-suited regions of Nepal for Moringa cultivation due to their elevation and climate conditions. It is commonly referred as "The Miracle Tree" due to its extensive practical and nutritional benefits as well as a remedy to cure many fatal diseases. Moringa is also a great supplement to provide essential amino acids, micronutrients, and protein to the typically nutrient-lacking rural Nepalese diet. Especially, pregnant women and infant are benefitted more through high nutrient content of leaves. Every part of Moringa has useful properties which can serve mankind and it can be one of the promishing plant for further research activities. The main purpose of this review was to highlight the nutritional, medicinal and commercial properties of Moringa, to know the potentiality of Moringa cultivation in the context of Nepal, to suggest future directions for research, market and development strategies and to assess the published scientific journal, article on multipurpose use of Moringa oleifera.
\end{abstract}

Keywords: Moringa oleifera; Miracle Tree; Nutritional; Medicinal; Nepal

\section{Introduction}

Moringa oleifera is an Angiospermic plant commonly known as the 'drumstick' or 'horseradish' tree. It belongs to genus Moringa having 13 different species. Among them, Moringa oleifera is the most widely cultivated species native to tropical and sub-tropical region of world [1]. Moringa oleifera is a tropical deciduous perennial dicotyledonous tree. It has different names in different countries like "Shiferaw" in Ethiopia and drumstick tree or horseradish tree in India and 'Sitalchini', Munga, Sahijan or Saijan in Nepal.

It is a small, graceful, deciduous tree with sparse foliage, belonging to family Moringaceae. The tree ranges from 5 to $10 \mathrm{~m}$ in height [2]. The Leaves are alternate, the old ones soon fall off and each leaf large up to about $90 \mathrm{~cm}$ long, with opposite pinnae. They are $5 \mathrm{~cm}$ away from the central stalk of the plant. Moringa contains slightly larger terminal leaflets with leaflets in opposite pairs. Leaflets are dark green above and pale on the under surface and variable in size and shape, but often rounded-elliptic, as much as $2.5 \mathrm{~cm}$ long.

Flowers are produced throughout the year, in loose axillary panicles up to $15 \mathrm{~cm}$ long. Fruit large and distinctive, up to $90 \mathrm{~cm}$ long and $12 \mathrm{~mm}$ broad, slightly constricted at intervals, gradually tapering to a point, 3- (4-) angled, with 2 grooves on each face. And they are light brown in colour. In order to expose the rows of rounded blackish oily seeds, each with 3 papery wings, it splits along each angle [3]. The tree shape is forked from the base area. Bark is smooth, dark grey slash thin and yellowish. The Twigs and shoots of the tree are short which have dense hair. The Crown is made up of single stem wide, open, and typically umbrella shaped. The tree is deep rooted and wood is soft [3]. Moringa oleifera is 
bisexual and highly cross-pollinated plant due to heteromorphism. The carpenter bees (Xylocopalatipes and X. pubescens) have been found the most reliable and appropriate pollinators for Moringa. The main purpose of this review was to highlight the nutritional, medicinal and commercial properties of Moringa, to know the potentiality of Moringa cultivation in the context of Nepal, to suggest future directions for research, market and development strategies and to assess the published scientific journal, article on multipurpose use of Moringa oleifera.

\section{Propagation}

Moringa oleifera can be propagated either from seeds, cuttings or both. Due to its high germination rate, direct seeding is possible. Moringa seeds can be germinated year-round in well-draining soil. For vegetative propagation, cuttings of $1 \mathrm{~m}$ length and at least $4 \mathrm{~cm}$ diameter can be used.

For intensive leaf production, "the spacing of plants should be $15 \times 15 \mathrm{~cm}$ or $20 \times 10 \mathrm{~cm}$, with conveniently spaced alleys (for example: every $4 \mathrm{~m}$ ) to facilitate plantation management and harvests. Sometimes, due to high density weeding and disease prevention are quite difficult. The plants are spaced at $50 \mathrm{~cm}^{*} 1 \mathrm{~m}$ apart during semi-intensive production. This gives good results with less maintenance. Moringa trees have huge benefit as a natural fences because it can be planted in alleys and also associated with other crops. In agro-forestry cultivation the distance between Moringa rows is usually $2 \mathrm{~m}$ and $4 \mathrm{~m}$.

\section{Harvesting}

Moringa trees can be harvested after reaching a height of $1.5 \mathrm{~m}$ and $2 \mathrm{~m}$ during high density cultivation. The leaves should be harvested by cutting the leaf stems with a sharp knife or snapping leaf stems from branches at $20 \mathrm{~cm}$ to $45 \mathrm{~cm}$ above the ground. This method promotes the development of new shoots [4]. It can be harvested up to 35 to 40 days. But in case of fodder harvesting, the tree should be harvested at every 75 days. The harvested leaves should not be heaped together, since they will spoil easily. Early Morning is the best time for harvesting which prevent excess loss of water. For selling the fresh leaves, they should be sold the same day since they lose moisture quickly after harvesting. Moringa can also be harvested at a height of $50 \mathrm{~cm}$ above ground level, which facilitates mechanical harvesting [5].

\section{Origin and distribution}

M. oleifera is native of the western and sub- Himalayan, India, Pakistan, Asia Minor, Africa and Arabia [6]. But it is now distribut- ed in the Philippines, Cambodia, Central America, North and South America and the Caribbean Islands [7]. For a variety of purposes, it is now cultivated in the whole tropical and sub-tropical regions of the world.

\section{Cultivation condition}

Moringa oleifera is a small to medium-sized, deciduous or evergreen tree mostly common in tropical, foot hills and some midhill region of Nepal [8]. It grows upto $25-30 \mathrm{ft}$ and the mid-hill, the siwalik and teraiarea is best for its cultivation [9]. It grows best in direct sunlight up to 0-1000 meter above sea level. Moranga can tolerates high range of soil conditions, but prefers neutral to slightly acidic (pH. 6.3-7.0). This shows its preferences towards well-drained sandy or loamy soil. The Minimum annual rainfall requirements is about $250 \mathrm{~mm}$ with maximum at over $3,000 \mathrm{~mm}$, but in waterlogged soil the roots have a tendency to rot. In order to encourage water run-of, trees can be planted on small hills in heavy rainfall prone area. The Presence of a long taproot makes the plant resistant to severe periods of drought. The best temperature range from 12-40 degree Celsius, but the tree will tolerate up to 48 degrees in the shade and it can survive a light frost [10]. It readily colonizes stream banks and savannah areas where the soils are well drained and the water table remains fairly high all the year round. Although, the plant is drought tolerant, it yields much less foliage when it is continuously under water stress. It is not harmed by frost, but can be killed back to ground level by a freeze. It quickly sends out new growth from the trunk when cut, or from the ground when frozen [4].

\section{Benefits of Moringa oleifera}

\section{Nutritional properties}

Moringa oleifera is called a 'Miracle Tree' due to its multipurpose nutritional uses and capacity to cure many diseases. Every part of plant has reserved nutrients. The Leaves of Moringa oleifera are rich source of minerals like calcium, potassium, zinc, magnesium, iron and copper. The Leaves has low calorific value so can be used in the diet of obese. The leaves also contain all essential amino acids and are rich in protein and minerals [11]. Pods contains around $46.78 \%$ fiber, $20.66 \%$ protein and are highly valued for curing digestive problem and colon cancer [12]. Vitamins like vitamin A, Vitamin B, Beta-carotene, pyridoxine, nicotinic acid, vitamin C, Vitamin D and E also present in abundant amount in Moringa oleifera. 
Moringa oleifera also contains major phytochemicals such as: tannin, sterols, terpenoids, flavonoids, saponins, anthraquinones, alkaloids and reducing sugar is also present along with anti-cancerous agents like glucosinolates, isothio cyanates, glycoside compounds and glycerol-1-9-octadecanoate. Oligosaccharides and oxalate were reported as anti-nutrient factor in Moringa leaves [13]. The Dried leaves (M. oleifera) retained $87.5 \%$ and $50 \%$ of $\beta$-carotene after 4 and 3 month storage, respectively, and could therefore be processed for convenient use [14].

The nutrient compositions of leaves, leaf powder, seeds and pods is shown in given table.

\begin{tabular}{|l|c|c|c|c|c|}
\hline Nutrients & $\begin{array}{c}\text { Fresh } \\
\text { leaves }\end{array}$ & $\begin{array}{c}\text { Dry } \\
\text { leaves }\end{array}$ & $\begin{array}{c}\text { Leaf } \\
\text { pow- } \\
\text { der }\end{array}$ & Seed & Pods \\
\hline Calories (cal) & 92 & 329 & 205 & - & 26 \\
\hline Protein (g) & 6.7 & 29.4 & 27.1 & $35.97 \pm 0.19$ & 2.5 \\
\hline Fat (g) & 1.7 & 5.2 & 2.3 & $38.67 \pm 0.03$ & 0.1 \\
\hline $\begin{array}{l}\text { Carbohydrate } \\
\text { (g) }\end{array}$ & 12.5 & 41.2 & 38.2 & $8.67 \pm 0.12$ & 3.7 \\
\hline Fibre (g) & 0.9 & 12.5 & 19.2 & $2.87 \pm 0.03$ & 4.8 \\
\hline $\begin{array}{l}\text { Vitamin B1 } \\
\text { (mg) }\end{array}$ & 0.06 & 2.02 & 2.64 & 0.05 & 0.05 \\
\hline $\begin{array}{l}\text { Vitamin B2 } \\
\text { (mg) }\end{array}$ & 0.05 & 21.3 & 20.5 & 0.06 & 0.07 \\
\hline $\begin{array}{l}\text { Vitamin B3 } \\
\text { (mg) }\end{array}$ & 0.8 & 7.6 & 8.2 & 0.2 & 0.2 \\
\hline $\begin{array}{l}\text { Vitamin C } \\
\text { (mg) }\end{array}$ & 220 & 15.8 & 17.3 & $4.5 \pm 0.17$ & 120 \\
\hline $\begin{array}{l}\text { Vitamin E } \\
\text { (mg) }\end{array}$ & 448 & 10.8 & 113 & $751.67 \pm 4.41$ & - \\
\hline Calcium (mg) & 440 & 2185 & 2003 & 45 & 30 \\
\hline $\begin{array}{l}\text { Magnesium } \\
\text { (mg) }\end{array}$ & 42 & 448 & 368 & $635 \pm 8.66$ & 24 \\
\hline $\begin{array}{l}\text { Phosphorus } \\
\text { (mg) }\end{array}$ & 70 & 252 & 204 & 75 & 110 \\
\hline $\begin{array}{l}\text { Potassium } \\
\text { (mg) }\end{array}$ & 259 & 1236 & 1324 & - & 259 \\
\hline Copper (mg) & 0.07 & 0.49 & 0.57 & $5.20 \pm 0.15$ & 3.1 \\
\hline Iron (mg) & 0.85 & 25.6 & 28.2 & - & 5.3 \\
\hline Sulphur (mg) & - & - & 870 & 0.05 & 137 \\
\hline
\end{tabular}

Table 1
The use of different parts of Moringa oleifera is described as below:

Leaves: The leaves of MO are considered to be a rich source of vitamins and minerals and exhibits strong antioxidant activity, often attributed to the plants' vitamins and phenolic compounds such asquercetin and kaempferol. The leaves can be also taken as vegetable and processed into tea, powder and other pharmaceuticals purpose. Further more, juice can be extracted from fresh leaves and act like growth harm one and increase crop yield by $25-35 \%$ [12]. According to Japanese study in 2009, leaves act as a good sink for carbon dioxide absorption and utilisation. The rate of assimilation of carbon dioxide by Moringa tree is 20 times higher then general vegetation [15]. Moringa is said to provide 7 times more vitamin $C$ than oranges, 10 times more vitamin A than carrots, 17 times more calcium than milk, 9 times more protein than yoghurt, 15 times more potassium than bananas and 25 times more iron than spinach [16].

Root: The root bark of Moringa has potential to cure gastric ulcers and gastric mucosal lesions. It also decreases the acidity and increases the $\mathrm{pH}$ of gastric juice. Hence, MO possesses antiulcer and anti secretary activity and hence, can be used as a source for antiulcer drugs in future.

POD husks: MO pod husks contain alkaloids, flavonoids, tannins, tritepenoids, diterpenoids and cardiac glycosides. MO pod husks extract show potential antimicrobial action against some gram positive staphylococcus epidermidis, Enterococcus faecalis and Gram negative Bacteria Klebsiella pneumonie and Salmonella typhimurium.

Seed: Moringa oleifera seed contains a range of phytochemicals, including antioxidants such as vitamin $C, \beta$-carotene, $\alpha$ and $\gamma$-tocopherol, $\beta$-sitosterol, vitamin $A$, the phenolic compounds quercetin and kaempferol, flavonoids, and anthocyanins, along with a few rare classes of compounds, including alkaloids, glucosinolates, and isothiocyanates. The mature seed of MO is rich in oil, containing between 22 and $40 \%$ crude fat. Examination of the oil composition indicates that the oil has a high proportion of monounsaturated fatty acids, particularly oleic acid. It has been demonstrated that a higher dietary intake of monounsaturated fatty acid (mainly oleic acid) is associated with decreased risk in coronary heart disease [17]. The seed extract could be used to prevent some 
vectors such as for malaria Anopheles stephensi mosquitoes. The phytochemicals derived from MO seeds extracts are effective mosquito vector control agents and the plant extracts may be used for further integrated pest management programs [18].

\section{Medicinal properties}

Moringa oleifera has several medicinal properties and has potentiality to cure many diseases. It is used to treat diseases such as diabetes, heart disease, anaemia, arthritis, respiratory problems, skin, liver problems, paralysis, sterility, rheumatism, digestive disorders and many more. In India, it was named the 'plant of the year' in 2008 by the National Institute of Health and Family Care. Several other countries like Africa, it is also used for the treatment of ascites, pneumonia and venomous bites. According to various research, the leaves are said to be anti-fungal, anti-viral, anti-abortifacient, and act as flocculating agent and stimulants. Moringa powder can be used as a substitute for iron tablet, hence a treatment for anaemia. The health benefits of this wonderful tree appear to be boundless. Apart from all the goodness discussed above, the regular intake of Moringa is said to help further.

\section{It fights Against free radicals}

The antioxidants are popular due to the fact as they fight against free radicals that cause oxidative stress, cell damage, and inflammation. In addition to this, Moringa contains antioxidants called flavonoids, polyphenols, and ascorbic acid in the leaves, flowers, and seeds which are beneficial in many ways. A study found that leaf extracts has higher antioxidant activity, free-radical-scavenging capacity, and higher inhibition of lipid, protein, and DNA oxidation than flowers and seeds. This means it prevents the damage and degradation that free radicals cause in the cells of different organs in the body, keeping them healthy and functioning at their best [19].

\section{Anti- inflammatory}

The most promising uses of Moringa extract is in the treatment of many types of chronic and acute inflammations.Inflammation can lead to chronic diseases like diabetes, respiratory problems, cardiovascular disease, arthritis, and obesity. Moringa reduces inflammation by suppressing inflammatory enzymes and proteins in the body, and leaf concentrate can significantly lower inflammation in the cells [20].

\section{Anti-diabetic}

Moringa has a huge role as a anti-diabetic. Its leaf powder is very effective at reducing lipid and glucose levels as well as regulating oxidative stress in diabetic patients, which means it lowers blood sugar and cholesterol level and improves protection against cell damage. Moringa has been presented to cure both Type 1 and Type 2 diabetes patients suffering from nonproduction of insulin, called Type 1 diabetes. Insulin is a hormone that maintains the blood glucose level of body. Type 2 diabetes is one linked with insulin resistance. Due to beta cell abnormal function, the type 2 diabetes is likely to occur. In this type of disorder, beta cell fails to detect glucose levels, hence reduces the signaling to insulin ensuring high blood glucose levels. Several studies have been proven that, Moringa can act as an antidiabetic agent [20].

\section{It protects the cardiovascular system}

Moringa leaf powder has heart-healthy benefits, particularly to control blood lipid, the prevention of plaque formation in the arteries, and reduced cholesterol levels. The great combination of diuretic along with lipid and blood pressure lowering components make this plant incredibly beneficial in cardiovascular disorders. Moringa leaf juice has very important role on stabilizing blood pressure. Mustard oil glycosides and thiocarbamate glycosides have been isolated from Moringa leaves, which had been observed to be responsible for lowering of blood pressure [20].

\section{Supports brain health}

Moringa strongly support for brain health and boost cognitive power due to its antioxidant and neuro-enhancer activities. It has shown several preliminary result as a treatment of Alzheimer's disease. The high amount of vitamin $\mathrm{C}$ and $\mathrm{E}$ helps to improve brain function and also normalize the neurotransmitters serotonin, dopamine and noradrenalin in the brain which play a key role in memory, mood, organ function, responses to stimulus such as stress and pleasure, and mental health like depression and psychosis.

\section{Hepato protective}

Moringa play very crucial role to protect liver against damage, oxidation, toxicity due to high concentrations of polyphenols in its leaves and flowers. Moringa oil can also restore liver enzymes to normal levels, reducing oxidative stress, and increasing protein content in the liver. The liver is responsible for blood detoxification, bile production, fructose metabolism, fat metabolism, and nutrient processing, and it can only fulfill these functions with the aid of liver enzymes, so it's vital they stay at normal levels. For instance, lower levels of hepatic enzymes can impair its ability to filter the blood. 


\section{Antimicrobial and antibacterial}

Moringa has antibacterial and anti-fungal properties that fight infections. It's been effective against types of fungi that cause infections on skin and strains of bacteria responsible for blood and urinary tract infections and digestive problems [21]. Roots of Moringa oleifera have antibacterial property and are described to be rich in antimicrobial agentsThe bark extract of Moringa has been found to have antifungal activities while the juice of the bark and stem exhibit antibacterial effect against Staphylococcus aureus.

\section{Enhances wound healing}

Moringa has blood-clotting properties in its leaves, roots, and seeds that benefit wound healing and can reduce clotting time, which means it reduces the time it takes for scratches, cuts, or wounds to stop bleeding. Antipyretic and wound healing properties from the ethyl acetate and ethanolic extracts of Moringa oleifera leaves were described by V.I. Hukkeri. The ethanolic and ethyl acetate extracts of seeds defines significant antipyretic activity in rats, where ethyl acetate extract of dried leaves presents wound healing activity (10\% extracts in the form of ointment) on excision, incision and dead space (granuloma) wound models in rats [22].

\section{Prospect of Moringa in the context of Nepal}

\section{Role to combat malnutrition}

Moringa oleifera, an edible tree found worldwide in the dry tropics, is increasingly being used for nutritional supplementation. The Food and Agriculture Organisation describes Moringa as a very useful plant with lots of health benefits. Some research articles have shown that Moringa is a plant that can help in reducing malnutrition among children and women. In the context of Nepal, malnutrition has been serious problem among children and pregnant women. According to Nepal, Demographic and health survey $2016,36 \%$ of children were stunting, $10 \%$ were wasted and $27 \%$ underweight [23]. Even though, the scenario is decreasing but not satisfactory and the mortality due to malnutrition is still prevalent in Nepal. So, Moringa oleifera could be a best option to reduce malnutrition problem.

Moringa oleifera contains various essential phytochemicals in its leaves, seeds and pods and it is one of the effective remedy for malnutrition [12]. Over 143 million children under the age of five in developing countries were undernourished in 2006 [24]. Food insecurity, lack of access to health care social, cultural, and economic class, all play a major role in explaining the prevalence of under-nutrition (West., et al. 2006). The climatic condition of $\mathrm{Ne}-$ pal favours the growth and development of Moringa oleifera, which can be one of the best option to reduce malnutrition. The Moringa is also considered as important famine food because of its high resistance to drought and arid conditions owing to their tuberous roots [25]. Furthermore, Moringa is said to provide 7 times more vitamin $\mathrm{C}$ than oranges, 10 times more vitamin A than carrots, 17 times more calcium than milk, 9 times more protein than yoghurt, 15 times more potassium than bananas and 25 times more iron than spinach [16].

The absolute number of people facing chronic food deprivation has increased to nearly 821 million in 2017, from around 804 million in 2016. Due to the incredible character of Morinaga to solve the hunger problem many international humanitarian organization and world health organization (WHO) have used it to combat malnutrition in many parts of the world. Over the long term, malnutrition in adolescents has a significant impact and they are at higher risk of suffering from infectious and metabolic diseases. Adolescent girls are at greater risk of malnutrition. Once adolescent girls have become mothers, prolonged malnutrition has adverse effects during pregnancy, which potentially cause premature delivery, maternal death, retarded foetal growth, low birth weight (LBW), and infant death. In addition to the health impact, malnutrition in adolescents can influence intellectual capability and school performance.

Moringa has abundant amount of calcium which is considered as one of the important minerals for human growth. While 8 ounces of milk can provide 300-400 mg, Moringa leaves can provide 1000 $\mathrm{mg}$ and Moringa powder can provide more than $4000 \mathrm{mg}$. Hence, can be used as a substitute of anaemia. It has been reported that higher amount of iron is present in Moringa than spinach [26]. A good dietary intake of zinc is essential for proper growth of sperm cells and is also necessary for the synthesis of DNA and RNA [27]. M. Oleifera leaves show around $25.5-31.03 \mathrm{mg}$ of zinc/ $\mathrm{kg}$, which is the daily requirement of zinc in the diet.

PUFAs are linoleic acid and oleic acid; these PUFAs have the ability to control cholesterol. Research show that Moringa seed oil contains around 76\% PUFA, making it ideal for use as a substitute for olive oil [28]. Depending upon the location and season of cultivation, the nutrient composition. The vitamin A content was found abundantly higher in the hot-wet season, while vitamin $\mathrm{C}$ and iron were more in the cool-dry season. Iron and vitamin A deficiencies, and infectious diseases continue to devastate people of the developing world; non-communicable diseases attributable to obesity 
are increasingly common in developed and developing countries. Diets rich in vegetables and fruits providing micronutrients and health-promoting phytochemicals could alleviate both under-nutrition and obesity. Insufficient vegetable and fruit consumption causes 2.7 million deaths annually worldwide and belongs to the top 10 risk factors contributing to mortality (Ezzati., et al. 2002). So, there is huge need of miracle plant like Moringa oleifera to combat Malnutrition for country like Nepal.

Role to alleviate poverty and rural livelihood improvement

Poverty and hunger related issues have continued to occupy a prominent position on the front burner of economic discuss over world, and developing Nations are facing a number of challenges regarding nutrition, health and standard of living. Inability of an individual to attain a minimum standard of living is poverty and it is a social condition characterized by in adequacy of access to basic human needs (food and non food) for the maintenance of socially acceptable standard of living in a given society.

Poverty occupies prominent position and this and this is a evident from [29] where it was reported that $1.4 \mathrm{~b}$ people out of the world population of $6.8 \mathrm{~b}$ live on $\$ 1.25$ a day or less [30], reported that an average of 22,000 children die each day due to poverty related conditions, while [31] puts the number of hungry people in the world at 925 million. Meaning that about one out every seven person is hungry. It further reported that $98 \%$ of the worlds hungry live in developing countries majorly Asia, Pacific and SubSaharan Africa. MDG report of 2010 confirmed that, a child dies from hunger related diseases every five seconds, while three out of every four persons worst hit by poverty and hunger live in the rural areas (HDR, 2010). Despite the fact that the rural communities have agriculture as their mainstay, FAO [31] reported that 50\% of hungry people are farm families in rural communities. It is argued that while poverty is the principal cause of hunger, hunger also causes poverty by bringing about poor health and low levels of energy thereby impeding productivity and resulting in poverty. About 95,000 to 16 million plant can be cultivated in one hector of land with $2 \mathrm{~kg}$ of leaves per harvest and can be harvested up to 10 years [32].

Due to the multipurpose use of Moringa, it can be a best option for rural poor, small holder farmer and marginalized community for livelihood improvement. It is one of the potential cash crop in terai, foot hills and mid hill region of Nepal. It can be intercropped with many other vegetables and has potentiality to increase rural income by generating employment, self sustainability, and alleviate poverty [8]. It is a drought tolerant plant So, requires less irrigation and less amount of manure and fertilizer. Moringa cultivation is not labour intensive, even family members can take part during their leisure time for its maintenance. The crop proves more profitable with minimum investment even within a small land in a short span of time. Therefore the crop can be a blessing to the rural community of Nepal.

Inadequate health care supply, poor nutrition, low income levels, use of trees and their by- products for provision of food, medicine and cosmetics are common among the rural people of the developing nations. Moringa Tree has been reported to be a wonder plant that is useful for human and animal nutrition, health, cosmetics, bio-gas and water purification among other uses. Empirical evidences on the economics of its production highlights its potential as a tool for enhancing the income of its producers.

\section{Potentiality of Moringa in Churia region}

There is high possibility of growing Moringa in the Churia range. As it is a fast growing tree and also a drought tolerant which is able to grow well in poor soil conditions or marginal lands with minimal rainfall. Moringa can be a good option for reclaiming such marginal land. Most of the land in Chure is marginal with fragility and poor nutrient conditions. Also, Moringa grows well in a temperature range of $25^{\circ} \mathrm{C}$ to $35^{\circ} \mathrm{C}$, but it also tolerates light frosts and temperatures up to $48^{\circ} \mathrm{C}$. The plant contains high levels of protein and make a good nutrient supporter to poor farmers. It reduces the dependency on forest for fuel wood. It can also be used as windbreaks, living fence and as a trellis or shade trees. It has also capacity off free flowering and amenable cash crop for varied ecosystems including marginal lands and farming systems. Therefore this plants, if grown in Chure range including flooded, waste land and river bank, where it may hold a large position with the prosperity of environment and economy in Nepal.

\section{Conclusions and Recommendation}

The potentials of Moringa Tree to combat the duo of poverty and hunger remain unassailable. However, the low levels of awareness of the inherent benefits of the plants have challenged the level of its cultivation in some parts of Nepal. Other challenges to the cultivation of the plant include uncertainty of markets, inadequate knowledge about its cultivation and uses. The proper use of Moringa Tree solve a lot of problems arising from nutrition, health and general well being of the masses and conserve the Foreign exchange which 
is presently used in the importation of synthetic vitamins and mineral, putrefying chemicals, convectional drugs, body and hair care products, and make more funds available for Rural Development programme. All rural farmers need to be encouraged to embark in planting of Moringa Tree for their empowerment. The Government should launch various programmes by providing trainings and other resources for the resource poor rural farmers, assist them in harvesting and processing, and pay them according to their yield. This form of empowerment will reduce poverty in the line and make Moringa Tree available for every household. Lastly, Agricultural extension and advisory services can play a big role in meeting the challenges and assisting rural farmers harness the enormous opportunities in the production and usage of Moringa Tree. Hence, Moringa tree will turn to be one of the most potential cash crop in the context of developing country like Nepal.

\section{Bibliography}

1. Olson M. (n.d.). "Combining data from DNA sequences and morphology for a phylogeny of Moringaceae". In Systemic Botany 55-73.

2. Anwar F., et al. "Moringa oleifera: A Food plant with multiple Medicinal uses". Wiley Inter science (2006).

3. Orwa. "Agroforestry database 4.0". World Agroforestry Center (2009).

4. Fredalette. Moringa production: Production guidelines for the Miracle tree (2018).

5. Mabapa M., et al. "Effect of planting density and harvest Interval on the leaf yield and Quality of Moringa under diverse Agroecological condition of Northern south Africa". International Journal of Agronomy 9 (2017).

6. Somali M., et al. "Chemical composition and characteristics of Moringa peregrina seeds and seeds oil". Journal of American oil Chemist's Society (1984): 85-86.

7. Morton FJ. "The Horseradish Tree, Moringa pterygosperma (Moringaceae): A boon to arid lands". Economic botany (1991): 318-333.

8. Pokhrel P., et al. "Moringa oleifera- A potential cash crop in Nepal". Healthy Society and Healthy World (2016).

9. Singh M. "The tree of life: Moringa Oleifera". Online khabar (2017).
10. Leone A., et al. "Cultivation, Genetic, Ethnopharmacology, Phytochemestry and Pharmacology of Moringa oleifera Leaves: An Overview". International Journal of Molecular Science (2015).

11. Janick J and Paull R. The Encyclipedia of Fruits and Nuts. Walling ford, United Kingdom: Cabi Publishing (2018).

12. Gopalkrishan L., et al. "Moringa oleifera: A review on nutritional importance and its medicinal application". Food Science and Human Wellness 8 (2016).

13. Freiberger C., et al. "Nutrient content of edible leaves of seven wild plants from Niger". In Plants Food for human Nutrition (1998): 57-69.

14. Glover AM and F M. "Nutritional evaluation of Moringa oleifera Leaves using three drying methods". Journal of Resistant Biology (2012): 469-473.

15. Daba, M. "Miracle tree: A review on multipurpose of Moringa oleifera and its Implication for climate change mitigation". Earth Science Climate Change (2016).

16. Gandhi K., et al. "Status and Utilization of Moringa oleifera Lam: A review". African crop science Journal 26 (2018): 137156.

17. Ghazali $\mathrm{H}$ and AS M. "Moringa (Moringa oleifera) Seed oil: Composition, Nutritional Aspects and Health Attributes" (2011).

18. Silva F., et al. "The many health benefit of Moringa oeifera". Journal of Medical and Pharmaceutical Innovation (2014).

19. Dixit S., et al. "Medicinal properties of Moringa oleifera: A Review". International Journal of Education and Science Research Review (2016).

20. Chaudhary K and Chaurasia, S. "Neutraceutical Properties of Moringa oleifera : A Review". European journal of Pharmaceutical and medical research (2017): 646-655.

21. Khor Z., et al. "The in- vivo and in-vitro anticancer properties of Moringa". Hindawi (2018).

22. VI H., et al. Indian Journal of Pharma Science (2006): 214-126.

23. Survey D. a. Nepal (2016).

24. UNICEF. Program for children: A world fit for children statistical Review Number (2008). 
25. CN K., et al. "Nutritional evaluation of indigenous foods and potential food based solution to alleviate hunger and malnutrition in kenya". Journal of Applied Biosciences 67 (2013).

26. Fuglie L. "The Moringa tree: A local solution to malnutrition church world service in Senegal" (2005).

27. Braminas JC and Emmanuel D. "Mineral composition of nonconventional leafy vegetables". Plant Foods Human Nutrition (1996): 29-36.

28. Lalas S and Tsaknis J. "Characterization of Moringa oleifera seed oil variety periyakulam" (2002).

29. IFAD. Rural poverty report (2011).

30. UNICEF. Humanitarian Action Report (2010).

31. FAO. The state of food and Agriculture (2010).

32. Fadliyah Kartikasari RL., et al. "Malnutrition treatment of adloscent girls using Moringa Chocolate cookies. The 8th annual basic science International conference. American Institute of physics.

Volume 3 Issue 11 November 2019

(C) All rights are reserved by Kantilata Thapa. 